
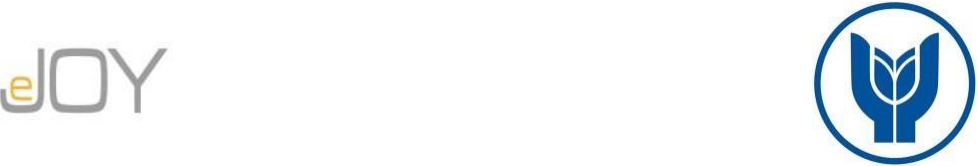

Demir, Y., Dinç, M. / Journal of Yasar University, 2021, 16/64, 1642-1657

\title{
Kredi Temerrüt Swapları, Döviz Kuru ile Borsa İstanbul Arasındaki İlişkinin Analizi
}

\section{An Analysis of the Relationship between Credit Default Swaps, Exchange Rate and Borsa Istanbul}

\author{
Yusuf DEMİR, Cumhuriyet Üniversitesi, Türkiye, ydemir@ cumhuriyet.edu.tr \\ Orcid No:0000-0001-5677-8709 \\ Mehmet DİNÇ, Ağrı İbrahim Çeçen Üniversitesi, Türkiye, mdinc@agri.edu.tr \\ Orcid No: 0000-0002-9864-8117
}

\begin{abstract}
Öz: Bu çalışmanın amacı, Türkiye'nin 2015-2020 dönemine ait günlük veriler yardımıyla CDS ile Borsa Ístanbul Endeksi ve döviz kuru arasındaki ilişkiyi incelemektir. Bu amaca yönelik olarak çalışmada yapısal kırllmaya izin veren birim kök testleri, çok kurlmaya izin veren eşbütünleşme testi ile Toda ve Yamamoto nedensellik testi kullanılmıştır. Yapısal kırılmaya izin veren birim kök testlere göre, döviz kuru ve CDS verilerinde istatistiksel olarak anlamlı kırllmaların olduğu görülmektedir. Eşbütünleşme test sonucuna göre ise, değişkenler arasında rejim kırlmalı bir ilişkinin söz konusu olduğu görülmektedir. Son analiz olan nedensellik testine göre, CDS ve Borsa İstanbul Endeksi'nin döviz kurunu etkilediği görülmektedir.
\end{abstract}

Anahtar Sözcükler: CDS, BIST, Döviz Kuru, Yapısal Kırılma

JEL Sinıflandirması: C58, G10, G15

Abstract: This study used data on the daily 2015-2020 period to examine the relationship between CDS, Borsa Istanbul Index and Turkey's exchange rate. Fort's purpose is to use the unit root tests that allow structural breaks, the cointegration test that allows multiple breaks, and the Toda and Yamamoto causality test. According to unit root tests that allow structural breaks, it is seen that there are statistically significant breaks in the exchange rate and CDS. According to the cointegration test result, it is seen that there is a regime break relationship between the variables. According to the causality test, which is the last analysis, it is seen that the CDS and Borsa Istanbul index affect the exchange rate.

Keywords CDS, BIST, Exchange Rate, Structural Break

JEL Classification: C58, G10, G15

\section{Giriş}

Kredi türev piyasasında oldukça sık kullanılan araçlardan biri olan kredi temerrüt takasları (CDS); esasen temelde, diş piyasalarda ihraç edilen bonolara yönelik koruma sağlayan, alacaklı tarafın, alacağının riskini, borç alan dışındaki üçüncü bir kişiye, belirli bir nakdi değer yani prim karşılığında transfer etmesine olanak tanıyan; borç konusu olan şeyin temerrüdü durumunda, alacaklının ödemiş olduğu primlerin karşılığını oluşturan borcun karşılığını CDS satıcısından, sözleşmede yer alan şartlar karşılığında tahsil etme hakkı tanıyan ve bu sayede kredi riskini karşı tarafa transfer ederek, temerrüt sonucunda oluşan kaybın azami seviyede azaltılmasını ve hatta mümkün olduğunca ortadan kaldırmasını sağlarlar (Hull, 2009:22). Belirli bir borç ödenmediğinde/ödeyemediğinde, borcu ödeyen bu finansal sözleşmeler 
(Bishop, 2013:221), herhangi bir kredinin geri ödenememesi riskine yönelik olarak yapılan sigortaya benzer bir işleve sahiptir (Fabozzi ve Anson vd., 2004:47).

1990’ların sonlarında, borçların ödenmeme riskine karşı geliştirilen CDS (Ateş, 2004:6), gelişmekte olan piyasalarda tahvil ve bono fiyatlarının değerlendirilmesinde önemli bir araç olarak; bir firmanın ya da bir ülkenin kredi borcunu ya da tahvil borcunu geri ödeyememe konusunda önemli bir boşluğu doldurmuştur (Canbaş ve Doğukanlı, 2007:151-156).

CDS uluslararası piyasaların bir ülkeye bakışını, o ülkeyi nasıl gördüğünü, yabancı yatırımcının tavrını gösteren önemli göstergelerden biridir. Bu çalışmanın amacı da, gelişmekte olan ülke konumunda yer alan Türkiye'nin 2015-2020 döneminde günlük veriler doğrultusunda CDS ile Borsa İstanbul Endeksi (BIST) ve döviz kuru arasındaki ilişkiyi incelemektir. Çalışmanın amacına yönelik olarak geleneksel birim kök testleri yanı sıra yapısal kırılmaya izin veren Ziwot-Andrews (1992) ve Narayan ve Popp (2010) birim kök testlerine yer verilmiştir. Ayrıca çalışmada kullanılan değişkenler arasındaki ilişki Maki (2012) tarafından tasarlanan ve çoklu kırılmayı sağlayan eşbütünleşme testi yardımıyla incelenmiştir. Çalışmanın sonunda değişkenler arasında var olan neden sonuç ilişkisinin yönü Toda ve Yamamoto (1995) nedensellik testi yardımıyla belirlenmiştir. Çalışmada öncelikle Türkiye'ye yönelik yapılmış olan önceki çalışmaların yer aldığı literatür taramasına yer verilecektir. Nihayetinde çalışmada yer alan veri seti ve yöntemin tanıtıldığı veri seti ve yöntem kısmına daha sonra ise bu yöntemler sonucunda elde edilen bulgulara ve çalışmanın son kısmında ise çalışmanın elde edilen bulgular çerçevesinde genel değerlendirmenin yer aldığı sonuç kısmına yer verilecektir.

\section{Literatür Taraması}

İlk kez Duffie (1999) tarafından başlatılan (Akkaya, 2016:131) CDS ile ilgili yazın incelendiğinde, bu konuya yönelik gerçekleştirilen incelemelerin genel olarak 2008 küresel finans krizi sonrası kredi derecelendirme kuruluşlarının duyurduğu kredi notlarının kredi riskini belirlemede çok da yeterli olmadığı eleştirisi başladıktan sonra hızlanmıştır (Sevil ve Ünkaracalar, 2020:289).

Tablo 1. İlgili Literatür

\begin{tabular}{|c|c|c|c|c|}
\hline Yazar & Dönem & Değişken & Yöntem & Sопис̧ \\
\hline Fung vd. (2008) & 2001-2007 & $\begin{array}{l}\text { ABD borsa endeksi ve } \\
\text { CDS }\end{array}$ & VAR Analizi & $\begin{array}{l}\text { Borsa endeksi ile CDS } \\
\text { arasında } \\
\text { volatilite/fiyatlama } \\
\text { açısından karşılıklı ilişki } \\
\text { vardır. }\end{array}$ \\
\hline $\begin{array}{l}\text { Ghosh ve } \\
\text { Herwadkar (2009) }\end{array}$ & 1998-2008 & $\begin{array}{l}\text { Portföy hareketleri ve } \\
\text { finans piyasaları }\end{array}$ & VAR Analizi & $\begin{array}{l}\text { Portföy hareketleri, hisse } \\
\text { senetlerinde ve döviz } \\
\text { kurlarında değişikliklere } \\
\text { neden olur. }\end{array}$ \\
\hline
\end{tabular}




\begin{tabular}{|c|c|c|c|c|}
\hline $\begin{array}{l}\text { Ball ve Yllmaz } \\
(2012)\end{array}$ & $2002-2012$ & $\begin{array}{l}\text { CDS ile İMKB100 } \\
\text { endeksi }\end{array}$ & $\begin{array}{l}\text { Korelasyon } \\
\text { katsayisi ve } \\
\text { regresyon analiz }\end{array}$ & $\begin{array}{l}\text { CDS ile İMKB100 } \\
\text { arasında ters yönlü ilişki } \\
\text { vardır. }\end{array}$ \\
\hline Köseoğlu (2013) & $2005-2012$ & $\begin{array}{l}\text { CDS ve BİST100 } \\
\text { endeksi }\end{array}$ & $\begin{array}{l}\text { VAR Analizi ve } \\
\text { BEKK-GARCH } \\
\text { Modeli }\end{array}$ & $\begin{array}{l}\text { CDS ile hisse senedi } \\
\text { getirileri arasında negatif } \\
\text { ilişki vardır. }\end{array}$ \\
\hline $\begin{array}{l}\text { Asandului } \quad v d . \\
(2015)\end{array}$ & 2004-2014 & $\begin{array}{l}\text { CDS primleri ile ülke } \\
\text { borsaları }\end{array}$ & $\begin{array}{l}\text { Johansen } \\
\text { Eşbütünleşme } \\
\text { analizi }\end{array}$ & $\begin{array}{l}\text { Finansal krizlerin } \\
\text { öncesinde ve sonrasinda, } \\
\text { CDS primleri } \\
\text { borsalardaki } \\
\text { fiyatlamaları etkiler. }\end{array}$ \\
\hline $\begin{array}{l}\text { Kaya, Kaya ve } \\
\text { Laçiner (2015) }\end{array}$ & $2007-2014$ & $\begin{array}{l}\text { Derecelendirme } \\
\text { kuruluşları notları ve } \\
\text { CDS'ler }\end{array}$ & $\begin{array}{l}\text { Çoklu doğrusal } \\
\text { regresyon } \\
\text { yöntemi }\end{array}$ & $\begin{array}{l}\text { Derecelendirme notları } \\
\text { ve CDS'ler aynı olaylara } \\
\text { her zaman aynı tepkiyi } \\
\text { vermez. }\end{array}$ \\
\hline $\begin{array}{l}\text { Acaravcl ve } \\
\text { Karaömer (2017) }\end{array}$ & $2012-2017$ & $\begin{array}{l}\text { CDS ve } \\
\text { endeksi }\end{array}$ & Nedensellik testi & $\begin{array}{lr}\begin{array}{l}\text { CDS ile } \\
\text { endeksi }\end{array} & \begin{array}{r}\text { BIST100 } \\
\text { arasında }\end{array} \\
\text { nedensellik } & \text { ilişkisi } \\
\text { yoktur. } & \end{array}$ \\
\hline $\begin{array}{l}\text { Bektur ve } \\
\text { Malcioğlu (2017) }\end{array}$ & $2000-2017$ & $\begin{array}{l}\text { CDS ve BİST100 } \\
\text { endeksi }\end{array}$ & $\begin{array}{l}\text { HackerHatemi-J } \\
\text { nedensellik testi }\end{array}$ & $\begin{array}{l}\text { CDS'den Borsa'ya doğru } \\
\text { tek yönlü bir ilişki vardır. }\end{array}$ \\
\hline $\begin{array}{l}\text { Çonkar ve Vergili } \\
\text { (2017) }\end{array}$ & $2010-2015$ & $\begin{array}{l}\text { CDS primi ile döviz } \\
\text { kuru }\end{array}$ & $\begin{array}{l}\text { Johansen } \\
\text { eşbütünleşme, } \\
\text { Granger } \\
\text { nedensellik testi }\end{array}$ & $\begin{array}{l}\text { Döviz kurundan } \\
\text { CDS'lere tek yönlü } \\
\text { nedensellik ilişkisi } \\
\text { vardır. }\end{array}$ \\
\hline $\begin{array}{l}\text { Danacl, Şit ve Şit } \\
\text { (2017) }\end{array}$ & $2009-2016$ & $\begin{array}{l}\text { CDS, büyüme ve } \\
\text { Eurobondlar }\end{array}$ & $\begin{array}{l}\text { Toda-Yamamoto } \\
\text { nedensellik testi }\end{array}$ & $\begin{array}{l}\text { Ekonomik büyümeyle } \\
\text { CDS değişkenleri } \\
\text { arasında çift yönlü } \\
\text { nedensellik ilişkisi } \\
\text { vardır. }\end{array}$ \\
\hline $\begin{array}{l}\text { Akkuş ve Sakarya } \\
\text { (2018) }\end{array}$ & 2001-2017 & CDS ile likidite riski & $\begin{array}{l}\text { Kayan pencere } \\
\text { nedensellik } \\
\text { yaklaşımı }\end{array}$ & $\begin{array}{l}2010 \text { ve } 2016 \text { hariç diğer } \\
\text { dönemlerde ilişki yoktur }\end{array}$ \\
\hline $\begin{array}{l}\text { Foncesa ve } \\
\text { Gottschalk (2018) }\end{array}$ & $2007-2010$ & $\begin{array}{l}\text { CDS primleri ile pay } \\
\text { senedi piyasaları }\end{array}$ & VAR analizi & $\begin{array}{l}\text { CDS primleri, pay senedi } \\
\text { getirileri ve oynaklığ } 1 \\
\text { etkiler. }\end{array}$ \\
\hline $\begin{array}{l}\text { Mazak ve Özkul } \\
(2018)\end{array}$ & 2014-2019 & CDS ile Eurobondlar & $\begin{array}{l}\text { Toda-Yamamoto } \\
\text { nedensellik testi }\end{array}$ & $\begin{array}{l}\text { Değişkenler arasında çift } \\
\text { yönlü nedensellik vardır }\end{array}$ \\
\hline Münyas (2018) & $2007-2017$ & $\begin{array}{l}\text { CDS, BİST100 } \\
\text { endeksi, dolar kuru ve } \\
\text { gösterge tahvil faiz } \\
\text { oranı }\end{array}$ & Regresyon & $\begin{array}{l}\text { CDS primi ile BİST } 100 \\
\text { endeksi arasında ters bir } \\
\text { ilişki vardır. }\end{array}$ \\
\hline $\begin{array}{l}\text { Sovbetov ve Saka } \\
\text { (2018) }\end{array}$ & $2008-2015$ & $\begin{array}{l}\text { CDS ve BİST100 } \\
\text { endeksi }\end{array}$ & ARDL yaklaşımı & $\begin{array}{l}\text { Değişkenler uzun } \\
\text { dönemde dengeye } \\
\text { yaklaşmaktadır. }\end{array}$ \\
\hline $\begin{array}{l}\text { Şahin ve Özkan } \\
\text { (2018) }\end{array}$ & 2012-2017 & $\begin{array}{l}\text { CDS, döviz kuru ve } \\
\text { BİST100 endeksi }\end{array}$ & $\begin{array}{l}\text { Engle-Granger } \\
\text { eşbütünleşme } \\
\text { analizi }\end{array}$ & $\begin{array}{l}\text { CDS ile BIST100 } \\
\text { arasında çift yönlü } \\
\text { nedensellik vardır }\end{array}$ \\
\hline $\begin{array}{l}\text { Özpınar, Özman } \\
\text { ve Doru }(2018)\end{array}$ & $2005-2017$ & CDS ile döviz kuru & $\begin{array}{l}\text { Johansen } \\
\text { eşbütünleşme; } \\
\text { Granger } \\
\text { nedensellik testi }\end{array}$ & $\begin{array}{l}\text { CDS ile kur arasında } \\
\text { uzun dönemli pozitif bir } \\
\text { ilişki vardır. }\end{array}$ \\
\hline Kahyaoğlu (2019) & 2013-2018 & CDS ile döviz kuru & $\begin{array}{lr}\text { Yüksek } & \text { frekansli } \\
\text { zaman } & \text { serisi } \\
\text { analizi } & \\
\end{array}$ & $\begin{array}{l}\text { Döviz kuru ile CDS'ler } \\
\text { arasında güçlü bir ilişki } \\
\text { vardır. }\end{array}$ \\
\hline Kllcı (2019) & $2000-2018$ & $\begin{array}{l}\text { CDS ile diş borç/ } \\
\text { GSYİH }\end{array}$ & $\begin{array}{l}\text { Fourier SHIN } \\
\text { Eşbütünleşme ve } \\
\text { Fourier Granger } \\
\text { nedensellik testi }\end{array}$ & $\begin{array}{l}\text { Değişkenlerin arasında } \\
\text { pozitif bir ilişki vardır. }\end{array}$ \\
\hline
\end{tabular}




\begin{tabular}{|c|c|c|c|c|}
\hline $\begin{array}{l}\text { Akın ve Işıklı } \\
(2020)\end{array}$ & $2007-2018$ & $\begin{array}{l}\text { CDS, ekonomik } \\
\text { büyüme ve cari açık }\end{array}$ & $\begin{array}{l}\text { Maki } \\
\text { eşbütünleşme ve } \\
\text { Toda-Yamamoto } \\
\text { nedensellik testi }\end{array}$ & $\begin{array}{l}\text { Cari açık ve ekonomik } \\
\text { daralma CDS'leri artırır. }\end{array}$ \\
\hline Evci (2020) & 2010-2019 & $\begin{array}{l}\text { CDS ve BİST100 } \\
\text { endeksi }\end{array}$ & $\begin{array}{l}\text { Johansen } \\
\text { eşbütünleşme; } \\
\text { Granger } \\
\text { nedensellik testi }\end{array}$ & $\begin{array}{l}\text { CDS ile BIST100 } \\
\text { arasında ters yönlü } \\
\text { nedensellik ilişkisi vardır }\end{array}$ \\
\hline $\begin{array}{l}\text { Sarıgül ve } \\
\text { Şengelen (2020) }\end{array}$ & 2014-2019 & $\begin{array}{l}\text { CDS ve BİST banka } \\
\text { endeksi }\end{array}$ & $\begin{array}{l}\text { Johansen } \\
\text { eşbütünleşme; } \\
\text { Granger } \\
\text { nedensellik testi }\end{array}$ & $\begin{array}{l}\text { Değişkenler } \\
\text { arasında uzun dönemli } \\
\text { ilişki vardır. }\end{array}$ \\
\hline $\begin{array}{l}\text { Sevil ve } \\
\ddot{U n k a r a c a l a r} \\
(2020)\end{array}$ & $2010-2018$ & $\begin{array}{l}\text { CDS ile portföy } \\
\text { yatırımları }\end{array}$ & $\begin{array}{l}\text { Johansen } \\
\text { eşbütünleşme; } \\
\text { Granger } \\
\text { nedensellik testi }\end{array}$ & $\begin{array}{l}\text { Portföy yatırımlarının } \\
\text { CDS üzerinde kısa } \\
\text { dönemde etkisi vardır. }\end{array}$ \\
\hline
\end{tabular}

\section{Veri Seti ve Yöntem}

Çalışma kapsamında yapılan incelemede Türkiye'nin 02.01.2015-31.12.2020 dönemine ait günlük veri seti yardımıyla döviz kuru, CDS ve BIST arasındaki ilişki incelenmektedir. Çalışmada kullanılan değişkenlerden döviz kuru (EX, \$/TL), ve BIST 100 kapanış değeri (BIST) Türkiye Cumhuriyeti Merkez Bankası tarafından hazırlanan Elektronik Veri Dağıtım Sistemi (EVDS) veri tabanından, Kredi Temerrüt Swapları (CDS, 5 yıllık ABD \$) veri seti ise, Datastream veri tabanından elde edilmiştir.

Çalışmada yöntem olarak geleneksel birim kök testleri, yapısal kırılmaya izin veren birim kök testleri ve eşbütünleşme testi ve son olarak nedensellik testi kullanılmıştır. Geleneksel birim kök ${ }^{1}$ testleri serilerde meydana gelen yapısal değişmeleri göz ard1 etmektedir. Ancak Perron (1989)'un belirttiği gibi, serilerin yapısal değişmesinin göz ardı edilmesi serilerin farklı durağanlık düzeylerine sahip olmalarına ve bu değişkenlerle kurulacak olan modellerde ise sahte ilişkinin kurulmasına neden olabilmektedir. Bu neden dolayı çalışmada Ziwot-Andrews (1992) ve Narayan ve Popp (2010) tarafından önerilen yapısal kırılmayı dikkate alan birim kök testlerine yer verilmiştir. Bu iki birim kök testlerin ortak özellikleri ikisi de "seri birim köke sahiptir” boş hipotezini test eden Genişletilmiş Dickey ve Fuller (Augumented Dickey and Fuller, ADF) test prosedürüne dayanmakta ve ikisi de kırılma tarihlerini içsel olarak belirlemektedir. Bu çalışmalardan Zivot ve Andrews (1992) çalışmalarında, düzeyde kırılmaya, eğimde kırılmaya ve gerek düzeyde gerekse eğimde kırılmaya yol açan üç farklı model geliştirmişlerdir. $\mathrm{Bu}$ üç modeller olan Model A, Model $\mathrm{B}$ ve Model $\mathrm{C}$ aşağıdaki gibi tanımlanmaktadır:

\footnotetext{
${ }^{1}$ Ayrıntılı bilgi için lütfen bakını, Dickey ve Fuller (1979, 1981), Elliott, vd. (1996), Phillips ve Perron (1987, 1988) ve Kwitkowski, vd. (1992)
} 
Model A: $y_{t}=\alpha+\delta D U(\lambda)+\beta t+\theta y_{t-1}+\sum_{j=1}^{k} \phi \Delta y_{t-j}+\varepsilon_{t}$

Model B: $y_{t}=\alpha+\beta t+\varphi D T(\lambda)+\theta y_{t-1}+\sum_{j=1}^{k} \phi \Delta y_{t-j}+\varepsilon_{t}$

Model C: $y_{t}=\alpha+\delta D U(\lambda)+\beta t+\varphi D T(\lambda)+\theta y_{t-1}+\sum_{j=1}^{k} \phi \Delta y_{t-j}+\varepsilon_{t}$

$$
D U(\lambda)=\left(\begin{array}{cc}
1 & t>T B \\
0 & t \leq T B
\end{array}\right) \quad D T(\lambda)=\left(\begin{array}{cc}
t-T B & t>T B \\
0 & t \leq T B
\end{array}\right)
$$

Burada DU, DT, TB ve $\lambda$ sırasyıla sabitte kırılma kukla değişkeni, eğimde kırılma kukla değişkenini, kırılma tarihini ve kırılma kesrini göstermektedir. Minimum t değeri serideki kırılma nıktasını belirlemektedir (Zivot ve Andrews, 1992). Çalışmada yer alan diğer yapısal kırılmaya dikkate alan birim kök testi olan Narayan ve Popp (2010) çalışmasında, ADF test tipi testlerin boş hipotezi sahte reddetme problemi olduğunu savunan çalışmalara eleştirimiştir. Çalışmalarında sahte reddetme probleminin kırılma tarihini etkileyen parametrelerin farklı hipotezler altında farklı yorumlanmasından kaynaklandığını vurgulamaktadırlar. Narayan ve Popp (2010)'e göre, bu problem Schmidt ve Phillips (1992) çalışmasında yer alan gözlenemeyen bileşenlerdeki veri yaratma süreci takip edilerek ortadan kaldırılabilir. ADF tipi Narayan ve Popp (2010) yapısal kırılmaya yol açan veren birim kök testini Zivot ve Andrews (1992) çalışmasından ayıran özellik hem düzeyde hem de düzeyde ve eğimde iki yapısal kırılmaya izin vermesidir. Buna göre ADF test prosedürüne dayalı iki yapısal kırılamaya izin veren denklem aşağıdaki gibidir:

$$
\begin{gathered}
y_{t}=Z_{t}+\varepsilon_{t} \\
\varepsilon_{t}=\rho \varepsilon_{t-1}+v_{t} \\
v_{t}=\psi^{*}(L) e_{t}=A^{*}(L)^{-1} B(L) e_{t}
\end{gathered}
$$

Burada $\mathrm{Z}_{\mathrm{t}}$ ve ${ }^{\varepsilon_{t}}$ sırasıyla determinisitk ve stokastik bileşenşleri göstermektedir. $\mathrm{Z}_{\mathrm{t}}$ düzeyde iki kırılmaya izin veren (M1) ve hem düzeyde hem de eğimde iki kırılmaya izin veren (M2) şeklinde iki farklı biçimde belirlenmektedir. $Z_{\mathrm{t}}$ 'nin iki farklı formu aşağıdaki gibidir:

$$
Z_{t}^{M 1}=\alpha+\beta t+\psi^{*}(L)\left(\delta_{1} D U_{1, t}+\delta_{2} D U_{2, t}\right)
$$




$$
\begin{gathered}
Z_{t}^{M 2}=\alpha+\beta t+\psi^{*}(L)\left(\delta_{1} D U_{1, t}+\delta_{2} D U_{2, t}+\varphi_{1} D T_{1, t}+\varphi_{2} D T_{2, t}\right) \\
D U_{i, t}=1\left(t>T B_{i}\right), \quad D T_{i, t}=1\left(t>T B_{i}\right)\left(t-T B_{i}\right), \quad i=1,2
\end{gathered}
$$

Burada $\delta$ parametresi düzeydeki, $\varphi$ parametresi ise eğimdeki kırılma büyüklüğünü göstermektedir. $\psi^{*}(L)$ parametresi ise determinisitk bileşende meydana gelen kırılmaların yavaş bir biçimde ortaya çıkmasını sağlamaktadır. Deterministik bileşeni veri yaratma süreci denkleminde yerine koyduğumuzda aşağıdaki gibi olacaktır:

$$
\begin{aligned}
& y_{t}^{M 1}=\rho y_{t-1}+\alpha_{1}+\beta * t+\phi_{1} D(T B)_{1, t}+\phi_{2} D(T B)_{2, t}+\delta_{1} D U_{1, t-1}+\delta_{2} D U_{2, t-1} \\
& +\sum_{j=1}^{k} \gamma \Delta y_{t-j}+e_{t} \\
& y_{t}^{M 2}=\rho y_{t-1}+\alpha_{1}+\beta * t+\kappa_{1} D(T B)_{1, t}+\kappa_{2} D(T B)_{2, t}+\delta_{1} D U_{1, t-1}+\delta_{2} D U_{2, t-1} \\
& +\phi_{1} D T_{1, t-1}+\phi_{2} D T_{2, t-1}+\sum_{j=1}^{k} \gamma \Delta y_{t-j}+e_{t}
\end{aligned}
$$

Burada $\kappa_{i}=\left(\phi_{i}+\gamma_{i}\right), \delta_{i}^{*}=\left(\gamma_{i}-\vartheta \phi_{i}\right) v e \vartheta=\rho-1$ göstermektedir. ADF test tipi birim kök testi $\rho=1$ boş hipotezi test etmektedir. Kırılma tarihi $\arg \max _{T B} \mid t_{\kappa, \phi}(T B)$ tarafından belirlenmektedir (Narayan ve Popp, 2010).

Yapısal kırılmanın bulunması durumunda, eğer değişkenler arasındaki ilişki yapısal kırılmayı göz ardı eden Engle ve Granger (1987) veya Johansen (1981,1991) ile test edilirse, değişkeler arasındaki ilişki yanlış belirlenmiş olacaktır. Diğer taraftan, eğer değişkenler arasında iki yapısal kırılma varsa ve tek yapısal kırılamaya izin veren Gregory ve Hansen (1996) eşbütünleşme testi ile uzun dönem ilişki aranırsa veya değişkenler arasında tek yapısal kırılma varsa ve Hatemi-j (2008) tarafından önerilen iki yapısal kırılmaya yön veren eşbütünleşme testi ile değişkenler arasında uzun dönem ilişkinin varlığı test edilirse yine aynı şekilde yanlış belirleme sorunu ortaya çıkacaktır. Eğer değişkenler arasında ikiden fazla yapısal kırılma varsa bu durumda her iki test de geçerliliğini kaybetmiş olacaktır. Buradan hareketle, değişkenler arasındaki ilişki çoklu kırılma ile test eden eşbütünleşme test modelleri aşağıdaki gibidir (Maki, 2012):

Model 1: Sabitte kırılmaya izin veren eşbütünleşme modeli:

$$
y_{t}=\mu+\sum_{i=1}^{k} \mu_{i} D_{i, t}+\alpha^{\prime} x_{t}+u_{t}
$$


Model 2: Hem sabitte hem de eğimde kırılmaya izin veren eşbütünleşme modeli:

$$
y_{t}=\mu+\sum_{i=1}^{k} \mu_{i} D_{i, t}+\alpha^{\prime} x_{t}+\sum_{i=1}^{k} \alpha_{i}^{\prime} x_{t} D_{i, t}+u_{t}
$$

Model 3: Trendli rejimde kırılmaya izin veren eşbütünleşme modeli:

$$
y_{t}=\mu+\sum_{i=1}^{k} \mu_{i} D_{i, t}+\delta t+\alpha^{\prime} x_{t}+\sum_{i=1}^{k} \alpha_{i}^{\prime} x_{t} D_{i, t}+u_{t}
$$

Model 4: Sabitte, trendde ve eğimde kırılmaya izin veren eşbütünleşme modeli

$$
\begin{gathered}
y_{t}=\mu+\sum_{i=1}^{k} \mu_{i} D_{i, t}+\delta t+\sum_{i=1}^{k} \delta_{i} t D_{i, t}+\alpha^{\prime} x_{t}+\sum_{i=1}^{k} \alpha_{i}^{\prime} x_{t} D_{i, t}+u_{t} \\
D_{i, t}\left(\begin{array}{l}
1 t>T B_{i} \\
0 t \leq T B_{i}
\end{array}\right)
\end{gathered}
$$

Burada, $y_{t}, x_{t}=\left(x_{1 t}, \ldots ., x_{m t}\right)^{\prime}, D_{i, t}, \mathrm{~TB}_{\mathrm{i}}, u_{t}$ ve k sırasıyla, bağımlı değişkeni, açıklayıcı değişken vektörünü, kırılmalara ait kukla değişkenini, kırılma tarihini, hata terimini ve kırılma sayısını göstermektedir. "Değişkenler arasında eşbütünleşme ilişkisi yoktur” boş hipotezine sahip olan eşbütünleşme testinin belirsiz kırılma tarihi ve kırılma sayısı tıpkı Bai ve Perron (1998) tarafından önerilen yapısal kırılma testi ile Kapetanios (2005) tarafından geliştirilen yapısal kırılmalı birim kök testi gibi belirlenmektedir (Maki, 2012).

Çalışmanda geleneksel ve yapısal kırılmalı birim kök testleri ve yapısal kırılmalı eşbütünleşme testinin ardından değişkenler arasındaki ilişkinin yönünü belirlemek amacıyla Toda ve Yamamoto (1995) tarafından sunulan nedensellik testine yer verilmiştir. Vektör otoregresyon (vector autoregression, VAR) modeline dayalı olan bu nedensellik testinin en önemli özelliği değişkenlerin durağanlık düzeylerinin ve değişkenler arasındaki uzun dönem ilişkinin varlığının aranmamasıdır. Toda ve Yamamoto nedensellik testinde değişkenler arasında nedensellik yoktur boş hipotezinin sınandığı VAR modeline dayalı nedensellik testi aşağıdaki gibidir:

$$
Y_{t}=\alpha+\beta_{1} Y_{t-1}+\ldots+\beta_{p+d_{\max }} Y_{t-p-d_{\max }}+\varepsilon_{t}
$$

Burada, p ve $d_{\max }$ sirasıyla uygun gecikme uzunluğunu ve maksimum eşbütünleşme derecesini göstermektedir. Değişkenler arasındaki nedensellik ilişki, p serbestlik dereceli asimptotik olarak Ki-kare dağılımına sahip olan Wald test istatistiği ile sınanmaktadır (Toda ve Yamamoto, 1992). 


\section{Bulgular}

Döviz kuru, CDS ve BIST arasındaki ilişkiyi inceleyen çalışmada yer alan değişkenlere ait geleneksel birim kök test sonuçlarına ilişkin veriler Tablo 1'de yer almıştır. Tablo 1 incelendiğinde, serilerin bütün geleneksel birim kök test sonuçlarına göre düzey değerlerinde durağan olmadığı görülmektedir. Bununla beraber serilerin birinci farkının alındığı serilerin durağan olduğu görülmektedir. Diğer bir deyişle, çalışmada yer alan tüm seriler I (1) düzeyinde bulunmaktadir.

Tablo 2. Geleneksel Birim Kök Test Sonuçları

\begin{tabular}{|c|c|c|c|c|c|c|c|c|c|c|}
\hline & Değişkenler & $A D F$ & $\begin{array}{l}D F- \\
G L S\end{array}$ & $P P$ & $K P S S$ & Değişkenler & $A D F$ & $D F-G L S$ & $P P$ & $K P S S$ \\
\hline \multirow{3}{*}{ 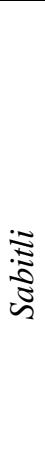 } & $L E X$ & $\begin{array}{l}-0.722 \\
(0.839)\end{array}$ & 2.019 & $\begin{array}{l}-0.718 \\
(0.840)\end{array}$ & $4.642 *$ & $\triangle L E X$ & $\begin{array}{l}-19.372 * \\
(0.000)\end{array}$ & $-3.160 *$ & $\begin{array}{l}-32.954 * \\
(0.000)\end{array}$ & 0.039 \\
\hline & $L C D S$ & $\begin{array}{l}-2.136 \\
(0.230)\end{array}$ & -1.056 & $\begin{array}{l}-2.087 \\
(0.250)\end{array}$ & $2.428^{*}$ & $\triangle L C D S$ & $\begin{array}{l}-34.370 * \\
(0.000)\end{array}$ & $-3.824^{*}$ & $\begin{array}{l}-34.299 * \\
(0.000)\end{array}$ & 0.065 \\
\hline & LBIST & $\begin{array}{l}-0.511 \\
(0.886)\end{array}$ & 0.006 & $\begin{array}{l}-0.681 \\
(0.849)\end{array}$ & $3.086^{*}$ & $\triangle L B I S T$ & $\begin{array}{l}-38.261 * \\
(0.000)\end{array}$ & $-3.363 *$ & $\begin{array}{l}-38.317 * \\
(0.000)\end{array}$ & 0.137 \\
\hline \multirow{3}{*}{ 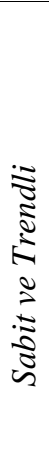 } & $L E X$ & $\begin{array}{l}-2.586 \\
(0.286)\end{array}$ & -2.592 & $\begin{array}{l}-2.610 \\
(0.275)\end{array}$ & $0.271^{*}$ & $\triangle L E X$ & $\begin{array}{l}-19.366^{*} \\
(0.000)\end{array}$ & $-5.697 *$ & $\begin{array}{l}-32.943 * \\
(0.000)\end{array}$ & 0.040 \\
\hline & $L C D S$ & $\begin{array}{l}-2.449 \\
(0.353)\end{array}$ & -2.453 & $\begin{array}{l}-2.231 \\
(0.415)\end{array}$ & $0.435^{*}$ & $\triangle L C D S$ & $\begin{array}{l}-34.364 * \\
(0.000)\end{array}$ & $-7.023^{*}$ & $\begin{array}{l}-34.283^{*} \\
(0.000)\end{array}$ & 0.059 \\
\hline & $L B I S T$ & $\begin{array}{l}-2.182 \\
(0.498)\end{array}$ & -1.756 & $\begin{array}{l}-2.364 \\
(0.398)\end{array}$ & $0.249 *$ & $\Delta L B I S T$ & $\begin{array}{l}-38.285 * \\
(0.000)\end{array}$ & $-5.972 *$ & $\begin{array}{l}-38.336 * \\
(0.000)\end{array}$ & 0.058 \\
\hline
\end{tabular}

Not: *,** sirasılla $\% 1$ ve $\% 5$ anlamlılık düzeyini göstermektedir.

Bilindiği gibi, geleneksel birim kök testleri serilerde meydana gelen yapısal değişmeleri göz ardı etmektedir. Serilerde meydana gelen yapısal değişimler serilerin durağanlık düzeylerinin farklı belirlenmesine neden olmaktadır. Buda seriler arasındaki ilişkinin sahte olmasına neden olabilmektedir. Buradan hareketle, çalışmadan kullanılan serilere ait yapısal kırılmayı göz önüne alan birim kök test sonuçları Tablo 2'de yer almaktadır. Elde edilen bulgulara göre, döviz 
kuru değişkeninin düzeyde iki kırılmaya izin veren ADF testine göre, 09.07.2018 ${ }^{2}$ ve 09.10.2018 3 tarihli, gerek düzeyde gerekse eğimde kırılmaya izin veren ADF testine göre ise, 22.01.2018 ${ }^{4}$ ve 09.10.2018 tarihli kırılma ile durağan olduğu görülmektedir. CDS değişkeninin de aynı döviz kuru değişkeni gibi tek kırılmaya izin veren birim kök test sonucuna göre durağan olmadığ1 ancak iki kırılmaya izin veren birim kök test sonucuna göre ise durağan olduğu görülmektedir. Yani, düzeyde iki kırılmaya izin veren test sonucuna göre, 27.04.2018 ${ }^{5}$ ve 17.02.2020 tarihli, hem düzeyde hem de eğimde kırılmaya izin veren test sonucuna göre ise, 27.04.2018 ve 03.03.20207 tarihli kırılma ile durağan olduğu tespit edilmiştir. Diğer taraftan çalışmada yer alan diğer bir değişken olan BIST değişkeninin gerek tek kırılmaya gerekse iki kırılmaya izin veren birim kök test sonuçlarına göre durağan olmadığı görülmektedir.

Tablo 3. Yapısal Kırılmayı Dikkate Alan Birim Kök Test Sonuçları

\begin{tabular}{|c|c|c|c|c|c|c|c|}
\hline \multirow{2}{*}{ Değişken } & \multirow{2}{*}{ Yöntem } & \multicolumn{3}{|c|}{ Model A: Düzeyde Kırllma } & \multicolumn{3}{|c|}{$\begin{array}{l}\text { Model C: Düzeyde ve Eğimde } \\
\text { Kirllma }\end{array}$} \\
\hline & & Test Ist. & Kesim & Kırılma Tarihi & Test İst. & Kesim & $\begin{array}{l}\text { Kirlma } \\
\text { Tarihi }\end{array}$ \\
\hline \multirow{5}{*}{ LEX } & Tek Kirılma & & & & & & \\
\hline & $A D F(Z \& A)$ & -4.194 & 0.559 & 30.04 .2018 & -4.117 & 0.559 & 30.04.2018 \\
\hline & İki Kırllma & & & & & & \\
\hline & $A D F(N \& P)$ & $-4.957 * *$ & 0.591 & 09.07 .2018 & $-5.177 * *$ & 0.513 & 22.01 .2018 \\
\hline & & & 0.631 & 09.10 .2018 & & 0.631 & 09.10 .2018 \\
\hline \multirow{5}{*}{$L C D S$} & Tek Kırılma & & & & & & \\
\hline & $A D F(Z \& A)$ & -4.016 & 0.558 & 27.04 .2018 & -3.898 & 0.558 & 27.04.2018 \\
\hline & İki Kırllma & & & & & & \\
\hline & $A D F(N \& P)$ & $-5.356 *$ & 0.558 & 27.04.2018 & $-5.605 *$ & 0.558 & 27.04.2018 \\
\hline & & & 0.854 & 17.02 .2020 & & 0.862 & 03.03 .2020 \\
\hline \multirow{4}{*}{ LBIST } & Tek Kırılma & & & & & & \\
\hline & $A D F(Z \& A)$ & -3.226 & 0.554 & 18.04 .2018 & -3.203 & 0.855 & 18.02 .2020 \\
\hline & İki Kırllma & & & & & & \\
\hline & $A D F(N \& P)$ & -3.890 & 0.140 & 03.11 .2015 & -4.557 & 0.337 & 04.01 .2017 \\
\hline
\end{tabular}

Not: Z\&A; Zivot ve Andrew,1992 (ADF), N\&P; Narayan ve Popp, 2010 (ADF), ve *, ** sirasiyla \% 1 ve \% 5 anlamlılık düzeyini göstermektedir.

\footnotetext{
${ }^{2}$ Cumhurbaşkanlığı Hükümet Sistemi'nin ilk Cumhurbaşkanı olan Recep Tayyip Erdoğan'ın yemin töreni ile yeni kabinenin açıklanması ile yeni Cumhurbaşkanlığı Hükümet Sistemi başlamıştır (https://www.aa.com.tr/tr/gunun-basliklari/iste-yenisistemin-ilk-kabinesi/1199235).

3 Enflasyonla Topyekun Mücadele Programı açıklanmıştır (https://www.aa.com.tr/tr/ekonomi/enflasyonla-topyekunmucadele-programi-aciklandi/1276638)

4 Zeytin Dalı Harekatı'nın 3. Gününde Azez'den Afrin'e operasyon başlatılmıştır (https://www.aa.com.tr/tr/gununbasliklari/tsk-afrine-azezden-operasyon-baslatti/1038508).

5 Türkiye Cumhuriyeti Merkez Bankası 25.04.2018 tarihinde 75 baz puan faiz arttırdığını açıklamıştır (https://www.iha.com.tr/haber-merkez-bankasi-faiz-kararini-acikladi-25-nisan-2018-723144/)

6 Türk ve Rus heyetlerinin Moskova'da İdlib Gerginliği Azaltma Bölgesi görüşmelerinin gerçekleştirilmesi (https://www.aa.com.tr/tr/dunya/turk-ve-rus-heyetleri-moskovada-idlibi-gorusuyor/1736398)

7 Amerika Birleşik Devletleri Merkez Bankası (FED) faiz indirimine gitmiştir (https://www.aa.com.tr/tr/ekonomi/feddensurpriz-faiz-indirimi-/1753404)
} 
Çalışmada yapısal kırılmaya izin veren birim kök testlerinin ardından yapısal kırılmaya izin veren eşbütünleşme testi sonuçlarına Tablo 3'te yer verilmiştir. Değişkenler arasındaki uzun dönem ilişkinin varlığı 4 farklı model ile incelenmiştir. Bu modellerden Model 2 olarak tanımlanan rejimde çoklu kırılmaya izin veren test sonuçlarına göre, döviz kuru, CDS ve BIST arasında 19.09.20178 / 23.02.20189 / 14.06.201810 / 07.03.201911 ve 01.07.201912 tarihli kırılmalar ile uzun dönem ilişki söz konusudur. Diğer model türlerine göre değişkenler arasında uzun dönem bir ilişki bulunmamaktadır.

Tablo 4. Yapısal Kırılmayı Dikkate Alan Eşbütünleşme Test Sonuçları

\begin{tabular}{|c|c|c|}
\hline Modeller & Test $\dot{I}_{\text {statistiğ } i}$ & Kırllma Tarihleri \\
\hline \multirow{5}{*}{ Model 1} & \multirow{5}{*}{-4.951} & 12.01 .2017 \\
\hline & & 19.09.2017 \\
\hline & & 23.02 .2018 \\
\hline & & 26.06.2018 \\
\hline & & 01.07 .2019 \\
\hline \multirow{5}{*}{ Model 2} & \multirow{5}{*}{$-6.772 *$} & 19.09 .2017 \\
\hline & & 23.02 .2018 \\
\hline & & 14.06.2018 \\
\hline & & 07.03.2019 \\
\hline & & 01.07 .2019 \\
\hline \multirow{5}{*}{ Model 3} & \multirow{5}{*}{-4.988} & 12.01 .2017 \\
\hline & & 19.09.2017 \\
\hline & & 23.02.2018 \\
\hline & & 14.06.2018 \\
\hline & & 01.07 .2019 \\
\hline \multirow{5}{*}{ Model 4} & \multirow{5}{*}{-6.667} & 20.06.2016 \\
\hline & & 24.02.2017 \\
\hline & & 19.09.2017 \\
\hline & & 07.03.2019 \\
\hline & & 01.07 .2019 \\
\hline
\end{tabular}

Not: *, ** sırasıyla $\% 1$ ve $\% 5$ anlamlılık düzeyini göstermektedir.

Çalışmanın son analizinde ise, değişkenlerin durağanlık düzeyinin ve değişkenler arasında eşbütünleşme ilişkisinin varlığının olup olmamasının önemli olmadığı Toda ve Yamamoto nedensellik testi yaklaşımı ile değişkenler arasında ilişkinin yönü belirlenmiştir. Tablo 4'e göre, CDS ve BIST değişkenlerinden döviz kuruna doğru tek yönlü bir neden sonuç ilişkisi bulunmaktadır. Diğer bir deyişle, CDS ve BIST'in döviz kurunu etkilediği görülmektedir. CDS ile BIST değişkenleri arasında ise herhangi bir nedensellik ilişkisinin bulunmadığı

\footnotetext{
${ }^{8}$ Amerika Birleşik Devletleri Merkez Bankası’nın (FED) Açık Piyasa Komitesi (FOMC) toplantısının gerçekleştirilecektir (https://www.aa.com.tr/tr/ekonomi/piyasalarin-gozu-fedde/913666)

${ }^{9}$ Hollanda Meclisi'nin 1915 olaylarını "soykırım” olarak kabul etmiştir (https://www.aa.com.tr/tr/gunun-basliklari/hollandamaslahatguzari-disisleri-bakanligina-cagrildi/1071546)

10 Amerika Birleşik Devletleri Merkez Bankası (FED) 13.06 .2018 tarihinde 25 baz puan faiz arttı̆̆ını açıklamıştır (https://www.aa.com.tr/tr/ekonomi/fed-beklenen-faiz-kararini-acikladi/1174312)

11 Türkiye Cumhuriyeti Merkez Bankası resmi rezerv miktarı 100 milyar dolar seviyesini geçmiştir (https://www.aa.com.tr/tr/ekonomi/merkez-bankasi-rezervleri-7-ayin-zirvesinde/1411787)

${ }^{12}$ G20 Liderler Zirvesi'nde yaşanan olumu gelişmeler yaşanmıştır (https://www.aa.com.tr/tr/turkiye/g20de-turkiye-ile-abdarasinda-s400-ve-f35-gundemi/1519184)
} 
görülmektedir. Yani Toda ve Yamamoto nedensellik test sonucuna göre, bu iki değişkenin birbirini etkilemediği sonucuna ulaşılmıştır.

Tablo 5. Nedensellik Test Sonuçları

\begin{tabular}{|c|c|c|c|c|c|}
\hline Hipotez. & $p$ & $d_{\max }$ & Wald & Ki-Kare p Değ. & Bootstrap p Dĕg. \\
\hline$L E X=>L C D S$ & 3 & 1 & 2.037 & 0.565 & 0.549 \\
\hline$L E X=>L B I S T$ & 3 & 1 & 0.313 & 0.958 & 0.949 \\
\hline$L C D S=>L E X$ & 3 & 1 & 494.157* & 0.000 & 0.000 \\
\hline$L C D S=>L B I S T$ & 1 & 1 & 1.902 & 0.168 & 0.164 \\
\hline$L B I S T=>L E X$ & 3 & 1 & $163.910 *$ & 0.000 & 0.000 \\
\hline$L B I S T=>L C D S$ & 1 & 1 & 2.157 & 0.142 & 0.117 \\
\hline
\end{tabular}

Not: LEX => LCDS, Döviz kuru CDS' in nedeni değildir hipotezini, *, ** sırasıyla $\% 1$ ve $\% 5$ anlamlılık düzeyini göstermektedir.

\section{Sonuç}

Kredi temerrüt swapları, alacaklının, alacağı konusunun riskini, borcun taraflarının dışında üçüncü kişilere belirli bir ücret karşılığında transfer etmesine olanak tanıyan türev araçlardan biri olması nedeniyle gerek hükümetler tarafından gerekse piyasada yer alan yatırımcılar açısından yakından takip edilmektedir. Özellikle Türkiye gibi kırılgan bir ekonomiye sahip olan gelişmekte olan ülkeler açısından CDS değeri, ülkeye yönelik yapılacak olan yatırım kararlarını önemli şekilde etkilemektedir. Dolayısıyla, kırılgan ekonomiye sahip olan ülkelere yapılan doğrudan ya da dolaylı yabancı yatırımlar hem döviz piyasasını hem de borsa işlemlerini etkileyebilmektedir. Buradan hareketle, bu çalışmanın amacı Türkiye'nin 02.01.201531.12.2020 dönemine ait günlük veriler yardımıyla döviz kuru, CDS ve borsa arasındaki ilişkiyi incelemektir. Bu amaca yönelik olarak çalışmada geleneksel birim kök testlerinin yanı sıra yapısal kırılmaya izin veren birim kök testleri ile eşbütünleşme testlerine yer verilmiştir. Ardından çalışmada yer alan değişkenler arasındaki ilişkinin yönünü belirlemek amacıyla Toda ve Yamamoto nedensellik testine yer verilmiştir. Yapısal kırılmalı birim kök testlerine göre, döviz kuru ve CDS'in çeşitli kırılma tarihleri ile durağan olduğu sonucuna ulaşılmıştır. Yapısal kırılmaya izin veren birim kök testinden sonra yapılan yapısal kırılmalı eşbütünleşme test sonucuna göre ise, değişkenler arasında rejimde çoklu kırılmaya izin veren modele göre, değişkenler arasında farklı kırılma tarihli uzun dönem ilişki bulunmaktadır. Çalışmada son olarak değişkenler arasındaki uzun dönem ilişkisinin yönünü belirlemeye yönelik yapılan nedensellik testine göre, Şahin ve Özkan (2018)'ın aksine, Acaravcı ve Karaömer (2017)'e paralel olarak CDS ve BIST'in kendi aralarında herhangi bir nedensellik ilişkisi bulunmazken, bu iki değişkenden Çonkar ve Vergili (2017)'nin aksine döviz kuruna doğru tek yönlü bir neden 
sonuç ilişkisi bulunmaktadır. Bu sonuç döviz kurunun hem CDS hem de BIST değişkeninden etkilendiğini göstermektedir.

Türkiye gibi gelişmekte olan ülkelere sermaye girişleri ekonomik aktiviteyi canlandırdığından, bu ülkelerin dış finansman kaynaklarına ihtiyaç duyması ve CDS primlerinin borsa ve döviz yatırımcılarının kararlarını belirlemede ve riski ölçmede kullandıkları önemli bir etken olmasından dolayı döviz kuru CDS ve BIST arasındaki ilişkileri anlamak önemlidir. Günümüzde sürdürülebilir kalkınma ve istikrarlı bir ekonominin tesisi için bu değişkenler adeta bir gösterge niteliğine gelmiştir. Bu değişkenlerde meydana gelebilecek değişiklikler yerli ve yabancı firmaların yatırım kararları ile tüketicilerin harcamaları üzerinde ve/veya bu değişkenlerde meydana gelen değişiklikler hem finansal, hem de reel sektör üzerinde etkiler meydana getirebilmektedir. Bu yüzden parasal otoriteler iktisat politikalarını oluştururken bu değişkenlerin seyrini dikkate almalıdırlar. 


\section{KAYNAKÇA}

Acaravc1, Songül Kakilli, and Mr Yunus Karaömer. 2017. "Borsa İstanbul (BİST-100) ve kredi temerrüt takası (CDS) arasındaki ilişkinin incelenmesi." Mediterranean International Conference on Social Sciences by UDG.

Akkaya, Murat. 2017. "Türk Tahvillerinin CDS Primlerini Etkileyen İçsel Faktörlerin Analizi." Maliye ve Finans Yazlarl 1 (107):130-145.

Akkuş, Hilmi Tunahan, and Şakir Sakarya. 2018. "Kredi Temerrüt Swapları İle Vade Farklarından Kaynaklanan Risk Primleri Arasındaki İlişki: Türkiye Üzerine Bir Uygulama." Yönetim ve Ekonomi: Celal Bayar Üniversitesi Íktisadi ve İdari Bilimler Fakültesi Dergisi 25 (3):735-747.

Asandului, Mircea, Dan Lupu, Gabriel Claudiu Mursa, and Radu Muşetescu. 2015. "Dynamic relations between CDS and stock markets in Eastern European countries."

Ateş, Gürkan. 2004. "Gelişmekte Olan Piyasalarda Kredi Temerrüt Swapları." Active Dergisi 34:9-20.

Bai, Jushan, and Pierre Perron. 1998. "Estimating and testing linear models with multiple structural changes." Econometrica:47-78.

Balı, S, and Z Yılmaz. 2012. "Kredi temerrüt takası marjları ile İMKB endeksi arasındaki ilişki. 16." Finans Sempozyumu Bildiri Kitapçı̆̆

Bektur, Çisem, and Gürkan Malcıoğlu. 2017. "Kredi temerrüt takaslari ile BİST 100 Endeksi arasindaki ilişki: Asimetrik nedensellik analizi." Bolu Abant İzzet Baysal Üniversitesi Sosyal Bilimler Enstitüsü Dergisi 17 (3):73-83

Bishop, M. 2013. "A’dan Z’ye Ekonomi Sözlüğü." Ş. Akın, B. Akın ve C. Yıldız (çev.). Ankara: Adres Yayınları (orijinal bask tarihi 2009).

Canbaş, Serpil, and Hatice Doğukanl1. 2007. Finansal pazarlar: finansal kurumlar ve sermaye pazarı analizleri: Karahan Kitabevi.

Çonkar, Mehmet Kemalettin, and Gizem Vergili. 2017. "Kredi temerrüt swapları ile döviz kurları arasındaki ilişki: türkiye için amprik bir analiz." Ömer Halisdemir Üniversitesi İktisadi ve İdari Bilimler Fakültesi Dergisi 10 (4):59-66.

Da Fonseca, José, and Katrin Gottschalk. 2020. "The Co-Movement of Credit Default Swap Spreads, Equity Returns and Volatility: Evidence from Asia-Pacific Markets." International Review of Finance 20 (3):551-579.

Danac1, M Cem, Şit Mustafa, and Şit Ahmet. 2017. "Kredi temerrüt swaplarının (CDS'lerin) büyüme oranıyla ilişkilendirilmesi: Türkiye örneği." Aksaray Üniversitesi İktisadi ve İdari Bilimler Fakültesi Dergisi 9 (2):67-78.

Dickey, David A, and Wayne A Fuller. 1979. "Distribution of the estimators for autoregressive time series with a unit root." Journal of the American statistical association 74 (366a):427-431.

Dickey, David A, and Wayne A Fuller. 1981. "Likelihood ratio statistics for autoregressive time series with a unit root." Econometrica: journal of the Econometric Society:1057-1072.

Duffie, Darrell. 1999. "Credit swap valuation." Financial Analysts Journal 55 (1):73-87.

Elliott, Graham, Thomas J Rothenberg, and James H Stock. 1992. Efficient tests for an autoregressive unit root. National Bureau of Economic Research Cambridge, Mass., USA.

Engle, Robert F, and Clive WJ Granger. 1987. "Co-integration and error correction: representation, estimation, and testing." Econometrica: journal of the Econometric Society:251-276.

Fabozzi, Frank J, and Moorad Choudhry. 2004. The handbook of European fixed income securities. Vol. 108: John Wiley \& Sons.

Fung, Hung-Gay, Gregory E Sierra, Jot Yau, and Gaiyan Zhang. 2008. "Are the US stock market and credit default swap market related?: Evidence from the CDX indices." The Journal of Alternative Investments 11 (1):43-61.

Ghosh, Saurabh, and Snehal Herwadkar. 2009. "Foreign portfolio flows and their impact on financial markets in India." Reserve Bank of India Occasional Papers 30 (3):51-72.

Gregory, Allan W, and Bruce E Hansen. 1996. "Residual-based tests for cointegration in models with regime shifts." Journal of econometrics 70 (1):99-126.

Hatemi-j, Abdulnasser. 2008. "Tests for cointegration with two unknown regime shifts with an application to financial market integration." Empirical Economics 35 (3):497-505.

Hull, John C. 2003. Options futures and other derivatives: Pearson Education India.

Johansen, Søren. 1988. "Statistical analysis of cointegration vectors." Journal of economic dynamics and control $12(2-3): 231-254$.

Johansen, Søren. 1991. "Estimation and hypothesis testing of cointegration vectors in Gaussian vector autoregressive models." Econometrica: journal of the Econometric Society:1551-1580.

Kahyaoğlu, Sezer Bozkuş. 2019. "Long Term Relatıonshıp Between CDS And Currency Exchange Rates: The Turkısh Case." Balıkesir Üniversitesi Sosyal Bilimler Enstitüsü Dergisi 22 (41):219-236. 
Kapetanios, George. 2005. "Unit-root testing against the alternative hypothesis of up to m structural breaks." Journal of Time Series Analysis 26 (1):123-133.

Kaya, Bekir, Emine Öner Kaya, and Kürşat Yalçıner. 2015. "Türkiye'nin derecelendirme notları ve kredi temerrüt swap primlerinin ekonomik ve sosyal olaylara tepkisinin analizi." Maliye ve Finans Yazlarl 1 (103):85111.

Kılcı, Esra N. 2019. "Dış Borçların Ülke CDS Primleri Üzerindeki Etkisinin İncelenmesi: Türkiye Örneği." Sayıştay Dergisi (112):75-92.

Köseoğlu, Sinem D. 2013. "The transmission of volatility between the cds spreads and equity returns before, during and after the global financial crisis: Evidence from turkey." Proceedings of 8th Asian Business Research Conference.

Kwiatkowski, Denis, Peter CB Phillips, Peter Schmidt, and Yongcheol Shin. 1992. "Testing the null hypothesis of stationarity against the alternative of a unit root: How sure are we that economic time series have a unit root?" Journal of econometrics 54 (1-3):159-178.

Maki, Daiki. 2012. "Tests for cointegration allowing for an unknown number of breaks." Economic Modelling 29 (5):2011-2015.

Mazak, Mehmet, and Gökhan Özkul. 2020. "Relationship Between Credit Default Swaps (CDS) and Government Bonds: A Study on Turkey." Anemon Muş Alparslan Üniversitesi Sosyal Bilimler Dergisi 8:243-256.

Münyas, Turgay. 2018. "CDS Primi ve Piyasa Göstergeleri Arasındaki İlişkinin Değerlendirilmesi Üzerine Ekonometrik Bir Analiz: Türkiye Örneği” Atlas International Refereed Journal on Social Sciences, 4(15): 1689-1696.

Narayan, Paresh Kumar, and Stephan Popp. 2010. "A new unit root test with two structural breaks in level and slope at unknown time." Journal of Applied Statistics 37 (9):1425-1438.

Özman, Hamit, Ömer Özpınar, and Doru Osman. 2018. "Kredi temerrüt takası (CDS) ve kur-faiz ilişkisi: Türkiye örneği." Bankacılık ve Sermaye Piyasası Araştırmaları Dergisi 2 (4):31-45.

Perron, Pierre. 1989. "The great crash, the oil price shock, and the unit root hypothesis." Econometrica: journal of the Econometric Society:1361-1401.

Phillips, Peter CB, and Pierre Perron. 1988. "Testing for a unit root in time series regression." Biometrika 75 (2):335-346.

Phillips, Peter CB. 1987. "Time series regression with a unit root." Econometrica: Journal of the Econometric Society:277-301.

Samet, Evci. 2020. "Kredi Temerrüt Swapları ile Borsa İstanbul Arasındaki Eşbütütünleşme İlişkisinin Analizi." Gaziantep Üniversitesi İktisadi ve İdari Bilimler Fakültesi Dergisi 2 (1):100-117.

Sarıül, Haşmet, and Hakan Eren Şengelen. 2020. "Ülke kredi temerrüt takas primleri ile hisse senedi fiyatları arasındaki ilişki: Borsa İstanbul'da banka hisse senetleri üzerine ampirik bir araştırma." Muhasebe ve Finansman Dergisi (86):205-222.

Schmidt, Peter, and Peter CB Phillips. 1992. "LM tests for a unit root in the presence of deterministic trends." Oxford bulletin of economics and statistics 54 (3):257-287.

Sevil, Güven, and Tutku Ünkaracalar. 2020. "CDS Primleri ile Portföy Yatırımları Arasındaki İlişkinin Değerlendirilmesi: Türkiye Örneği." Maliye ve Finans Yazılarl (113):285-300.

Sovbetov, Yhlas, and Hami Saka. 2018. "Does it take two to tango: Interaction between credit default swaps and national stock indices." Journal of Economics and Financial Analysis 2 (1):129-149.

Şahin, Eyyüp Ensari, and Oktay Özkan. 2018. "Kredi Temerrüt Takası, Döviz Kuru ve Bist100 Endeksi İlişkisi." Hitit Üniversitesi Sosyal Bilimler Enstitüsü Dergisi 11 (3):1939-1945.

Toda, Hiro Y, and Taku Yamamoto. 1995. "Statistical inference in vector autoregressions with possibly integrated processes." Journal of econometrics 66 (1-2):225-250.

Tuğba, Akın, and Emre Işıklı. "The Relationship Between Credit Default Swap, Economic Growth and Current Account Deficit: A Case of Turkey." Anemon Muş Alparslan Üniversitesi Sosyal Bilimler Dergisi 8:9198.

Zivot, Eric, and Donald W K Andrews. 2002. "Further evidence on the great crash, the oil-price shock, and the unit-root hypothesis." Journal of business \& economic statistics 20 (1):25-44.

İnternet Kaynaklar1

https://www.aa.com.tr/tr/gunun-basliklari/iste-yeni-sistemin-ilk-kabinesi/1199235 (Erişim tarihi: 03.02.2021)

https://www.aa.com.tr/tr/ekonomi/enflasyonla-topyekun-mucadele-programi-aciklandi/1276638 Erişim tarihi: 03.02.2021)

https://www.aa.com.tr/tr/gunun-basliklari/tsk-afrine-azezden-operasyon-baslatti/1038508 Erişim tarihi: 03.02.2021)

https://www.iha.com.tr/haber-merkez-bankasi-faiz-kararini-acikladi-25-nisan-2018-723144/ Erişim tarihi: 04.02.2021) 
https://www.aa.com.tr/tr/dunya/turk-ve-rus-heyetleri-moskovada-idlibi-gorusuyor/1736398 Erişim tarihi: 04.02.2021)

https://www.aa.com.tr/tr/ekonomi/fedden-surpriz-faiz-indirimi-/1753404 Erişim tarihi: 05.02.2021)

https://www.aa.com.tr/tr/ekonomi/piyasalarin-gozu-fedde/913666 Erişim tarihi: 05.02.2021)

https://www.aa.com.tr/tr/gunun-basliklari/hollanda-maslahatguzari-disisleri-bakanliginacagrildi/1071546 Erişim tarihi: 05.02.2021)

https://www.aa.com.tr/tr/ekonomi/fed-beklenen-faiz-kararini-acikladi/1174312 Erişim tarihi: 05.02.2021)

https://www.aa.com.tr/tr/ekonomi/merkez-bankasi-rezervleri-7-ayin-zirvesinde/1411787 Erişim tarihi: 06.02.2021)

https://www.aa.com.tr/tr/turkiye/g20de-turkiye-ile-abd-arasinda-s400-ve-f35-gundemi/1519184 Erişim tarihi: 06.02.2021) 